\title{
Price Discovery In The Soybean Futures Market
}

Bahram Adrangi, (Email: Adrangi@up.edu),University of Portland Arjun Chatrath,(Email: Chatrath@up.edu), University of Portland Kambiz Raffiee, (Email: Raffiee@unr.edu), University of Nevada, Reno

\begin{abstract}
This paper investigates the price discovery process between the nearby futures prices of soybean, soy meal, and soy oil contracts (Crush constituents) in the U.S. Relationships between these commodities may bear important implications for trading strategies, market inefficiencies, or the derived demand theory. Furthermore, our findings are relevant in light of market microstructure theories, which maintain that the price information disseminates from more liquid contracts. Our VAR and bivariate GARCH model estimates suggest a strong bi-directional causality in Crush futures prices. We also find that while soybean contracts bear the burden of convergence when the spread between soybean and soy meal contract prices widens, this is not true of soybean and soy oil contracts. Furthermore, we show evidence of considerable volatility persistence for the three contracts and volatility spillover between soybean and other Crush constituent futures. The statistical evidence suggests that information arrives in these markets simultaneously. Our findings do not support the derived demand theory.
\end{abstract}

\section{INTRODUCTION}

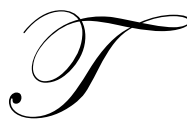

he price discovery process, by which market prices signal information, has been the subject of many papers in the past. Garbade and Silber (1979), Harris et al. (1995), Roell (1992), and Hashbrouck (1995), among others, are examples of studies that address the information signaling advantages of markets for single assets or indices. Others examine information flow between markets for similar assets or indices.

In this flow of research, Conrad and Kaul (1991) examine the information flow between large stocks and small stocks, and Hamao, Masulis, and $\mathrm{Ng}$ (1990), Karolyi and Stulz (1996) investigates information spillovers between US and foreign markets. Findings of these studies corroborate the belief that information disseminates from the more liquid markets where trading volume is concentrated. ${ }^{1}$

We investigate the discovery process between the spot prices of soybeans and soy meal and soy oil futures prices (Crush constituents) in the U.S. Dynamics of the information movements between these commodities may lead to new trading strategies or shed light on market inefficiencies.

Economic theory offers the derived demand theory to explain the relationship between the prices of products for final consumption and those for intermediate goods employed in the production process. According to this theory, the price of an intermediate good should be determined by its contribution to the market value of the manufactured good as reflected in its market price. Thus, we would expect the pricing information to flow from the product price back upstream to the intermediate good price. Therefore, if a causal relationship can be identified, we would expect it to flow from the prices of soy meal and soy oil to soybean prices, if derived demand inferences are to hold.

\footnotetext{
${ }^{1}$ Several authors including Blume, Easley, and O'Hara (1994) and Conrad, Hameed, and Niden (1994) also suggest that smaller firms have more predictable returns.
} 
Depending upon the strength of causality and the lead time found in the relationship between these prices, the knowledge of the relationship dynamics may provide the industry participants with useful information regarding the direction and timing of pricing changes for soybeans. If, on the other hand, the dynamics do not support the hypothesis of derived demand, we may conclude that differences in market power at various stages of the industry, e.g., harvest, conversion, versus marketing, break down the expected direction of price information flow, and may even reverse it. If the direction of information flow is reversed, i.e., causality is found to flow from soybean to soy products (intermediate good to final good), this information may still be of interest to market participants. Then changes in the observed price of soybean may be an indication of the likely change for the soy products.

The market structure changes along the continuum of this industry, and the interpretation may be dependent upon the assumptions. For example, the U.S. market is viewed as being fully exposed to international competition, so the soybean market may be viewed as competitive (any soybean producing country such as Brazil may enter this market).

The soy meal and soy oil sectors in the U.S. are populated by several major and independent operations. As such, this sector tends to be oligopsonistic/oligopolistic. Downstream, the wholesale buyers tend to be a bit more competitive than soybean processing and retailers perhaps even more competitive.

The quasi-oligopoly/oligopsony interaction in the soybean market and a fairly competitive output market in the U.S. lends further interest to the relationship between the prices of these two linked agricultural commodities. The lack of constancy of market structure along the industry continuum will tend to interrupt the dynamic flow of information that may otherwise be expected. Causality and information spillover findings in the U.S. market may offer interesting and useful information to market participants. Traders, soybean processors, and policy makers may be able to extract crucial information from the results of this paper.

In the U.S., soybean, soy oil and soy meal futures contracts are traded on the Chicago Board of Trade (CBT). Soybean is an international commodity with well-developed spot and futures markets. The importance of soybeans and its various derivatives such as soy meal and soy oil in the U.S. and the Fareast cannot be underestimated. Price fluctuations in the markets for these products has far reaching effects on the U.S. and world consumers, farmers, and soybean processors.

Another set of motives for examining the nature of the linkages among the Crush constituents is derived from market microstructure theories that relate the price discovery process to market liquidity or price volatility. Several financial models are predicated on the notion that trades are informative so that information disseminates from more liquid markets. For example, Verrecchia (1981) and Kim and Verrecchia (1991), among others, investigate the link between public information announcements and volume.

We employ daily closing nearby futures prices of soybeans, soy meal, and soy oil for the period spanning January 1969 through March 1999. The daily price data are obtained from the CBT. Returns are given by $100 * \ln \left(\mathrm{P}_{t} / \mathrm{P}_{\mathrm{t}-1}\right)$, or $100^{*} \Delta \ln \left(\mathrm{P}_{\mathrm{t}}\right)$, where $\mathrm{P}_{\mathrm{t}}$ is the price at the end of the day.

The two price pairs are shown to be cointegrated, indicating that they do not wonder off too far and price differences between soybean contract prices and other Crush constituents are mean reverting. We find that the information arrives in the three markets simultaneously. Soybean contracts bear the majority of the burden of convergence when price spreads between soybeans and soy meal widens however, that is not so for soy oil prices spreads. Furthermore, there is a strong evidence of bi-directional causality between the two contract pairs.

The organization of the rest of this paper is as follows. Section II presents the data and the methodology of this research. Empirical findings are discussed in section III. The last section presents a summary and conclusions. 


\section{DATA AND METHODOLOGY}

Daily closing nearby contract prices of soybeans, soy meal, and soy oil for the period spanning January 1969 through March 1999 are obtained from the CBT. Returns are given by $100 * \ln \left(\mathrm{P}_{\mathrm{t}} / \mathrm{P}_{\mathrm{t}-1}\right)$, or $100^{*} \Delta \ln \left(\mathrm{P}_{\mathrm{t}}\right)$, where $\mathrm{P}_{\mathrm{t}}$ is the price at the end of the day.

Prior research on information flows between markets has typically focused on lead-lag relationships between asset returns. Such an approach may provide only limited or biased inferences of information flows between markets. Informationaly linked markets may share some common stochastic trends, react asymmetrically to information, and/or exhibit time varying volatility. Failure to incorporate such effects can invalidate the statistical inferences relating to the relationships. Furthermore, it becomes important to recognize that information effects and volatility effects may be highly related (Ross (1989)), so that they must be studied together. This study employs a general approach to investigate the flow of information between the Crush constituents. The approach takes into account the time varying volatility in these commodities while allowing for intermarket volatility spillover, and asymmetrical effects of the variation in spreads.

Consider the VAR system:

$$
\begin{aligned}
& \Delta \ln P S B_{t}=\mu_{o}+\sum_{i=1}^{n} \mu_{i} \Delta \ln P S B_{t-i}+\sum_{i=1}^{n} \theta_{i} \Delta \ln P S M_{t-i}+\lambda_{S B}(\ln P S B-\ln P S M)_{t-i}+\varepsilon_{S B, t}(1) \\
& \Delta \ln P S M_{t}=\gamma_{o}+\sum_{i=1}^{n} \gamma_{i} \Delta \ln P S B_{t-i}+\sum_{i=1}^{n} \xi_{i} \Delta \ln P S M_{t-i}+\lambda_{S M}(\ln P S B-\ln P S M)_{t-i}+\varepsilon_{S M, t}(2),
\end{aligned}
$$

where, $\Delta \operatorname{lnPSB}_{t}$ and $\Delta \operatorname{lnPSM}_{t}$ are the returns on the soybeans and soy oil contracts, respectively, $(\ln P S B-\ln P S M)_{t-1}$ is the lagged difference in the log prices of the soybean and soy meal, which accounts for the convergence pressures in the two price series, and $\varepsilon_{\mathrm{SB}, \mathrm{t}}$ and $\varepsilon_{\mathrm{SM}, \mathrm{t}}$ are the random disturbance terms. The above error-correction specification is widely used to investigate the lead-lag relationship in financial markets. For instance, the estimation of significant coefficients on lagged changes in the soybean prices in soy meal (soy oil) equation would typically be interpreted as the existence of information flows from the soybean market to the soy meal (soy oil) market. The $\lambda$ coefficients, $-1 \leq \lambda_{\mathrm{SB}} \leq 0$ and $1 \geq \lambda_{\mathrm{SM}} \geq 0$ (with strict inequality for at least one coefficient), indicate the burden of convergence between the two commodities. If $\lambda_{\mathrm{SB}}<0$ and $\lambda_{\mathrm{SM}}=0$, then when the price spread widens the soybean contract prices fall in the process of convergence. Similarly, If $\lambda_{\mathrm{SM}}>0$ and $\lambda_{\mathrm{SB}}=0$, the soy meal price rises and converges to the soybean price as the spread between the two widens. As discussed later, the two prices are cointegrated so that and error correction term is warranted in equations (1) and (2).

There are strong reasons to suspect that the variance of the error terms in the above VAR equations are time varying. Theory suggests that informed trading will induce persisting changes in the volatility of these commodities (Kyle (1985)), and there is a great deal of evidence that many financial price series exhibit time varying volatility. Specific to debt securities, several researchers have argued that interest rate risk premia are time variant (for instance, Shiller (1979) and Singleton (1980)). Weiss (1984), Engle, Ng, and Rothschild (1990), and Engle, Lilien, and Robins (1987) find significant ARCH effects or serial correlation in variances in short-term rates over several decades. In the present study, variance persistence or clustering may arise from market features unique to these commodities' futures markets. For example, the daily price limit schemes in these markets clearly favors volatility persistence over large price jumps. ${ }^{2}$

There is also reason to suspect that these variance effects are correlated across the two contract pairs. Engle, $\mathrm{Ng}$, and Rothschild (1990) indicate that the underlying forces behind volatility for shorter end of term structure in interest rate contracts are common across different rates - indicative of co-persistence of variance. Such co-persistence will have important implications for empirical analysis of variance behavior. While commodity price series may exhibit high variance persistence in their univariate representations, this persistence may be common across related series, so that linear combinations of the variables show lesser persistence. Ross (1989) argues that volatility may be regarded as a measure of

\footnotetext{
${ }^{2}$ Price limits on soybean contracts are fairly common. This information not tabulated here is available from the authors.
} 
information flow. Thus, if information arrives first in the soybean market, one should see a volatility spillover from this market to the markets of the other Crush constituents. Therefore, to study the price dynamics in Crush constituents, an appropriate extension to the above VAR model will be employed to simultaneously allow for time varying volatility and volatility spillovers between the commodities.

The statistics in Table 1 justify some of the above suspicions relating to the variance of returns in the two series analyzed. The Ljung-Box $\mathrm{Q}(24)$ and $\mathrm{Q}^{2}(24)$ statistics indicate significant levels of serial correlation in returns and the square of the returns. These statistics indicate linear and nonlinear dependencies in daily prices. Test statistics for ARCH errors (Engle (1982)) further suggest serial correlation in the errors. On the other hand, there is less evidence of serial dependencies in the standardized residuals from fitting the returns to a GARCH $(1,1)$ model. ${ }^{3}$ The Q(24) statistics are substantially smaller and the $\mathrm{Q}^{2}(24)$ statistics are insignificant. Such evidence indicates that a basic GARCH model effectively captures the nonlinearities in the data. Moreover, the standardized residuals exhibit relatively smaller kurtosis, further evidence of the GARCH model providing a superior fit to the data (Hsieh (1989)).

Table 1: Preliminary Statistics For Daily Crush Prices

\begin{tabular}{|c|c|c|c|c|c|c|c|c|}
\hline Variable & $\mu$ & $\sigma$ & $\mathbf{S}$ & $\mathbf{K}$ & JB & $Q(24)$ & $Q^{2}(24)$ & $\operatorname{ARCH}(10)$ \\
\hline \multicolumn{9}{|c|}{ A. $\left(\ln p_{t}-\ln p_{t-1}\right) * 100$} \\
\hline$\overline{\text { SB }}$ & 0.006 & 1.66 & -0.748 & 13.74 & $36710.00^{* * * *}$ & $158.92^{* *}$ & $7921.5^{* * *}$ & $1366.00^{* * *}$ \\
\hline SM & 0.006 & 1.75 & -0.039 & 8.39 & $9065.65^{\text {**** }}$ & $112.14^{* * * *}$ & $9075.7^{* * * *}$ & $1575.14^{* *}$ \\
\hline $\mathrm{SO}$ & 0.011 & 1.81 & -0.506 & 10.49 & $17844.80^{* * * *}$ & $60.88^{* * * *}$ & $1390.9^{* * *}$ & $298.12^{* *}$ \\
\hline \multicolumn{9}{|c|}{ B. Standardized Return Residuals- Univariate GARCH $(1,1)$ Model } \\
\hline$\overline{\mathrm{SB}}$ & 0.015 & 0.999 & -.028 & 4.96 & $1313.88^{* * *}$ & $48.83^{* * *}$ & 19.32 & 9.22 \\
\hline SM & 0.015 & 0.999 & 0.22 & 7.08 & $5277.00^{* * *}$ & $49.27^{* * *}$ & 23.02 & 8.55 \\
\hline SO & 0.009 & 1.00 & -0.01 & 5.17 & $1474.80^{* * * *}$ & 17.81 & 14.93 & 20.8 \\
\hline
\end{tabular}

Notes: $\mu, \sigma, S$, and $\mathrm{K}$, are the mean, standard deviation, skewness, and kurtosis, respectively. JB is the Jarque-Bera statistic for normality test. Arch (10) is the Lagrange Multiplier test ( $\chi^{2}$ with p degrees of freedom) for ARCH errors (Engle (1982)). Higher order Arch errors also provided significant statistics in panel A and insignificant statistics in panel B. *, **, ***, represent significant at 10,5, and 1 percent levels, respectively. The GARCH $(1,1)$ model is given by

$$
\begin{aligned}
& R_{t}=\mu_{t-1}+\varepsilon_{t}, \\
& \varepsilon_{t} \mid\left(\varepsilon_{t-1}, \varepsilon_{t-2}, \ldots\right) \sim N\left(0, h_{t}\right) \\
& h_{t}=\alpha_{0}-\alpha_{1} \varepsilon_{t-1}^{2}+\alpha_{2} h_{t-1},
\end{aligned}
$$

Where $\mu_{\mathrm{t}-1}$ is the conditional mean, proxied by the lagged return, $\mathrm{R}_{\mathrm{t}-1}$

The relationship among the Crush constituents while simultaneously controlling for the likely variance and covariance persistence are studied via variations of the bivariate GARCH model (similar models have been employed by Hamao, Masulis and Ng (1990), Chan, Chan and Karolyi (1991), and Chatrath and Song (1998), among others)

$$
\begin{aligned}
& \sigma_{S B, t}=\alpha_{0}+\alpha_{1} \sigma_{S B, t-1}+\alpha_{2} \varepsilon_{S B, t-1}^{2}+\alpha_{3} \varepsilon_{S M, t-1}^{2}+u_{S M, t} \\
& \sigma_{S M, t}=\beta_{0}+\beta_{1} \sigma_{S M, t-1}+\beta_{2} \varepsilon_{S M, t-1}^{2}+\beta_{3} \varepsilon_{S B, t-1}^{2}+u_{S M, t}
\end{aligned}
$$

\footnotetext{
${ }^{3}$ We choose Bollerslev's (1986) GARCH $(1,1)$ model over higher order ARCH or GARCH models due to the strong support found for this model in recent work. Moreover, the GARCH $(1,1)$ model, with its fewer parameters, is more viable a multivariate setting (Baillie and Bollerslev (1990)).
} 
and

$$
\sigma_{S B, S M t}=\pi_{0}+\pi_{1} \sigma_{S B, S M t-1}+\pi_{2} \varepsilon_{S B, t-1} \varepsilon_{S M t-1}+u_{S B, S M, t}
$$

assuming

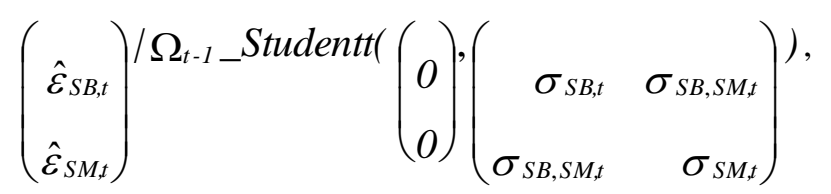

where $\sigma_{S B, t}$ and $\sigma_{S M, t}$ are the variance functions of $\square \varepsilon_{S B, t}$ and $\varepsilon_{S M, t} \square \square$ respectively, conditional on information set $(\Omega)$ available up to time $\mathrm{t}-1 ; \sigma_{S B, S M, t}$ represents the conditional covariance given by an autoregressive linear function of the cross product in the past squared errors; $\sigma_{\mathrm{SB}, \mathrm{SM}}$ represents the conditional covariance given by an autoregressive linear function of the cross products in the past squared errors; $u_{i t}$ are the randomly distributed regression errors; and the conditional correlation,

$$
\rho_{S B, S M, t}=\sigma_{S B, S M, t}\left(\sigma_{S B, t} \sigma_{S M, t}\right)^{-\frac{1}{2}}
$$

is allowed to vary over time.

The parameters $\alpha_{1}$ and $\beta_{1}$ in (3) and (4) are the measures of volatility persistence in the soybean and soy meal contract prices respectively, with a large value indicating that the conditional variance remains elevated for extended periods of time following return shocks. Parameters $\alpha_{3}$ and $\beta_{3}$ are intended to capture the volatility spillovers between markets. For instance, $\beta_{3}>0$ and $\alpha_{3}=0$ would be consistent with the hypothesis that the volatility spills over from the soybean market into the soy meal market, and not vice versa. Equations (3), (4), and (5) are later extended to examine the importance of the spread on the variance and covariance of the two returns.

\section{EMPIRICAL RESULTS}

Table 1 presents summary statistics. As was discussed above the summary statistics presented in Table 1 justify the methodology of this research. Tables 2 and 3 report the results of the stationarity and cointegration tests. The Augmented Dickey Fuller (Dickey and Fuller (1979) and Phillips-Perron test statistics (Phillips and Perron (1986)) reject the null hypotheses that the first difference in the natural logarithm of the Crush constituents futures price series are stationary, but cannot reject the null for the level series. Thus, as with most other commodity price series, there is evidence of one unit root in these futures prices. Further, the test statistics reject the null that the spreads (the difference in $\log$ of prices) are non stationary, providing evidence that the two series are cointegrated.

The Johansen trace and maximum-eigenvalue statistics (Johansen and Juselius (1990)) presented in Table 3 provide a direct test for cointegration of the Crush constituent's futures prices. The null hypotheses of zero cointegrating vectors between the two pairs of prices $(r=0)$ are rejected in both cases at the one percent level. We can conclude that there is at least one cointegrating vector between the pairs of futures. 
Table 2: Unit Root Test Statistics (Crush)

\begin{tabular}{|c|c|c|c|c|c|c|c|c|}
\hline \multirow[b]{3}{*}{ Contract } & \multicolumn{4}{|c|}{ Without Trend } & \multicolumn{4}{|c|}{ With Trend } \\
\hline & \multicolumn{2}{|c|}{$\underline{\operatorname{Ln}(p) * 100}$} & \multicolumn{2}{|c|}{$\Delta \ln (p) * 100$} & \multicolumn{2}{|c|}{$\underline{\operatorname{Ln}(p) * 100}$} & \multicolumn{2}{|c|}{$\Delta \ln (p) * 100$} \\
\hline & ADF & PP & ADF & PP & ADF & $\mathbf{P P}$ & ADF & PP \\
\hline SB & -2.32 & -2.23 & $-36.69^{* * * *}$ & $-81.12^{* * * *}$ & -2.17 & -2.05 & $-36.70^{* * * *}$ & $-81.20^{* * * *}$ \\
\hline SM & -2.01 & -1.97 & $-37.37^{* * * *}$ & $-81.83^{* * * *}$ & -1.87 & -1.83 & $-37.39^{* * *}$ & $-81.84^{* * *}$ \\
\hline SO & -1.64 & -1.61 & $-36.80^{* * * *}$ & $-81.54^{* * * *}$ & -1.48 & -1.45 & $-36.82^{* * *}$ & $-81.55^{* * *}$ \\
\hline Spread 1 & $-4.14^{* * *}$ & $-4.81^{* * * *}$ & & & $-4.48^{* * *}$ & $-5.23^{* * *}$ & & \\
\hline Spread 2 & $-4.40^{* * * *}$ & $-4.51^{* * * *}$ & & & $-4.40^{* * * *}$ & $-4.51^{* * * *}$ & & \\
\hline
\end{tabular}

Long-Term Equilibrium: Johansen-Juselius Maximum Likelihood Procedure Based on Maximal Eigenvalue and Trace of the Stochastic Matrix.

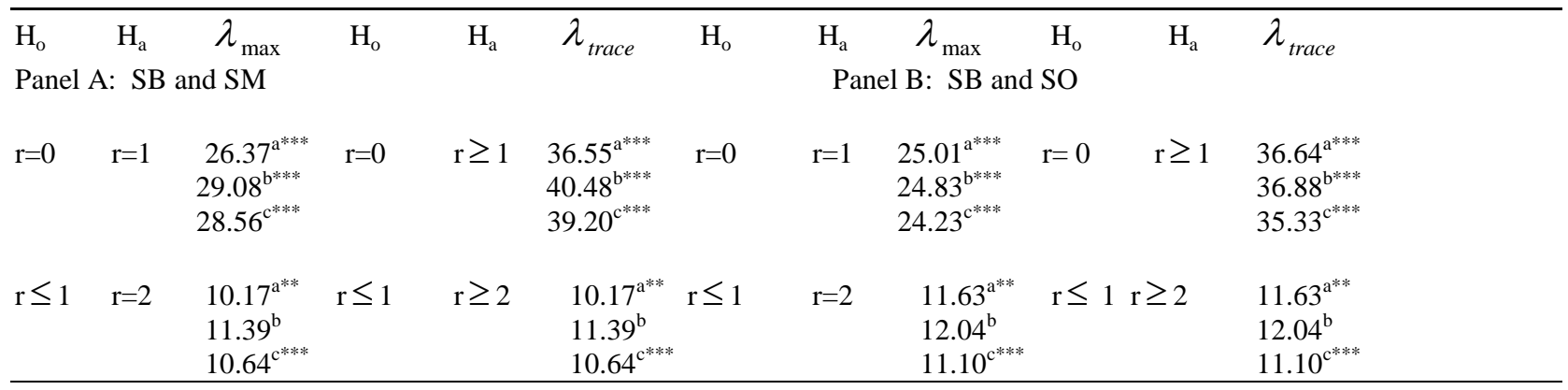

Notes: The ADF and PP stand for the Augmented Dickey-Fuller and Phillips-Perron test statistics of unit roots. The critical values of both statistics are provided by MacKinnon (1990). Variables included in the cointegrating vector are log of prices of soybean, soy meal and soy oil, and spreads are log price of soybean minus the log prices of soy meal and soy oil respectively. "r" stands for the number of cointegrating vectors. Critical values are taken from Oterwald-Lenum (1992). a. No deterministic trend in data, intercept but no trend in cointegrating equation. $\underline{b}$. Linear deterministic trend in data, intercept and trend in cointegration equation,

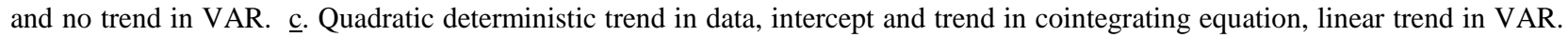
VAR order is seven and is determined by Akaike Information Criterion (AIC) and the log likelihood ratio test. $\stackrel{*}{*} \underset{* *}{-} \stackrel{* * *}{-}$, represent significant at 10,5 , and 1 percent levels, respectively.

Given prior evidence that the Johansen tests are sensitive to the inclusion of drift terms in its near-VAR specification (for instance, Diebold, Gardeazabal, and Yilmaz (1994)), it is worth noting that the Johansen tests provided similar results across models with and without controls for trend.

Table 3 presents the results from equations (1) and (2) estimated outside of the GARCH system. The lag length of seven is based on the Akaike information criterion. As there is strong evidence of a long run relationship between the spread-constituents series, an error correction term is appended to the VAR system. The specification produces independently distributed residuals as indicated by the $\mathrm{Q}(24)$ statistics. These results are later compared to those from the joint estimation of the mean and variance equations.

The $\chi$ squared statistics for the Wald test (W) reported in Table 3 suggest a strong bi-directional causality in futures prices. The significant negative coefficient of the lagged spread in the soybean price equation, coupled with the insignificant coefficient in the soy meal equation, suggests that the soybean contract bears the majority of the burden of convergence between the two prices. This is not true of soy oil. For example the significant positive coefficient of the lagged spread in the soy oil price equation, coupled with the insignificant coefficient in the soybean equation, suggests that the price convergence between soybeans and soy oil contracts do not occur and the price spread is bound to widen. This divergence in the behavior of the soy meal and soy oil in relation to soybean prices is worth a closer examination and may shed some light on the market structure for these products. 
Table 3: VAR Model With Error Correction - Dependent Variable: $100 * \Delta \ln (p)$

\begin{tabular}{|c|c|c|c|c|}
\hline & 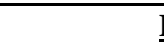 & & & \\
\hline & SB & SM & SB & SO \\
\hline Intercept & $\begin{array}{c}0.001^{* * * *} \\
(2.859)\end{array}$ & $\begin{array}{l}1.95 \mathrm{E}-05 \\
(0.059)\end{array}$ & $\begin{array}{c}0.0001 \\
(0.488)\end{array}$ & $\begin{array}{l}0.004^{* * * *} \\
(4.302)\end{array}$ \\
\hline & & & & \\
\hline$(\mathrm{t}-1)$ & $\begin{array}{c}0.008 \\
(0.597)\end{array}$ & $\begin{array}{l}0.084^{* * *} \\
(5.852)\end{array}$ & $\begin{array}{c}0.065^{* * * *} \\
(4.778)\end{array}$ & $\begin{array}{c}-0.007 \\
(-0.576)\end{array}$ \\
\hline$(\mathrm{t}-2)$ & $\begin{array}{l}-0.003 \\
(-0.242)\end{array}$ & $\begin{array}{l}5.54 \mathrm{E}-05 \\
(0.003)\end{array}$ & $\begin{array}{l}-0.038^{* * * *} \\
(-2.848)\end{array}$ & $\begin{array}{l}0.084^{* * * *} \\
(6.719)\end{array}$ \\
\hline$(\mathrm{t}-3)$ & $\begin{array}{c}-0.022 \\
(-1.473)\end{array}$ & $\begin{array}{l}0.056^{* * * *} \\
(3.879)\end{array}$ & $\begin{array}{c}-0.005 \\
(-0.407)\end{array}$ & $\begin{array}{l}0.033^{* * *} \\
(2.631)\end{array}$ \\
\hline$(\mathrm{t}-4)$ & $\begin{array}{l}-0.006 \\
(-0.453)\end{array}$ & $\begin{array}{c}0.021 \\
(1.498)\end{array}$ & $\begin{array}{c}0.019 \\
(1.386)\end{array}$ & $\begin{array}{c}-0.006 \\
(-0.530)\end{array}$ \\
\hline$(t-5)$ & $\begin{array}{l}-0.016 \\
(1.089)\end{array}$ & $\begin{array}{c}-0.007 \\
(-0.495)\end{array}$ & $\begin{array}{c}0.014 \\
(1.044)\end{array}$ & $\begin{array}{c}-0.004 \\
(-0.358)\end{array}$ \\
\hline$(t-6)$ & $\begin{array}{l}-0.044^{* * * *} \\
(-2.898)\end{array}$ & $\begin{array}{c}0.010 \\
(0.732)\end{array}$ & $\begin{array}{l}-0.047^{* * * *} \\
(-3.472)\end{array}$ & $\begin{array}{c}0.021^{*} \\
(1.678)\end{array}$ \\
\hline$(\mathrm{t}-7)$ & $\begin{array}{r}-0.045 \\
(-0.045)\end{array}$ & $\begin{array}{c}0.025^{*} \\
(1.760)\end{array}$ & $\begin{array}{l}-0.035^{* * *} \\
(-2.620)\end{array}$ & $\begin{array}{c}0.019 \\
(1.546)\end{array}$ \\
\hline & & & & \\
\hline$(\mathrm{t}-1)$ & $\begin{array}{c}0.208^{* * *} \\
(13.363)\end{array}$ & $\begin{array}{l}-0.074^{* * *} \\
(-4.951)\end{array}$ & $\begin{array}{l}-0.006 \\
(0.014)\end{array}$ & $\begin{array}{l}0.064^{\text {*** }} \\
(4.716)\end{array}$ \\
\hline$(\mathrm{t}-2)$ & $\begin{array}{l}-0.054^{* * * *} \\
(3.446)\end{array}$ & $\begin{array}{l}-0.099^{* * * *} \\
(-6.555)\end{array}$ & $\begin{array}{l}-0.000 \\
(-0.033)\end{array}$ & $\begin{array}{l}-0.009 \\
(-0.682)\end{array}$ \\
\hline$(\mathrm{t}-3)$ & $\begin{array}{l}-0.073^{* * * *} \\
(4.605)\end{array}$ & $\begin{array}{l}-0.038^{* *} \\
(-2.509)\end{array}$ & $\begin{array}{l}0.039^{* * * *} \\
(2.632)\end{array}$ & $\begin{array}{c}0.010 \\
(0.796)\end{array}$ \\
\hline$(\mathrm{t}-4)$ & $\begin{array}{l}0.066^{\text {**** }} \\
(4.152)\end{array}$ & $\begin{array}{l}-0.035^{\text {*** }} \\
(-2.322)\end{array}$ & $\begin{array}{c}0.005 \\
(0.399)\end{array}$ & $\begin{array}{c}0.013 \\
(0.951)\end{array}$ \\
\hline$(\mathrm{t}-5)$ & $\begin{array}{l}0.062^{* * * *} \\
(3.912)\end{array}$ & $\begin{array}{l}-0.035^{\text {** }} \\
(-2.344)\end{array}$ & $\begin{array}{c}0.031^{* *} \\
(2.093)\end{array}$ & $\begin{array}{c}-0.007 \\
(-0.541)\end{array}$ \\
\hline$(\mathrm{t}-6)$ & $\begin{array}{c}0.025 \\
(1.598)\end{array}$ & $\begin{array}{l}-0.029^{* * *} \\
(-1.942)\end{array}$ & $\begin{array}{c}0.007 \\
(0.502)\end{array}$ & $\begin{array}{c}-0.017 \\
(-1.284)\end{array}$ \\
\hline$(t-7)$ & $\begin{array}{c}-0.015 \\
(-0.015)\end{array}$ & $\begin{array}{c}0.023 \\
(1.606)\end{array}$ & $\begin{array}{l}-0.036^{* *} \\
(-2.444)\end{array}$ & $\begin{array}{c}0.012 \\
(0.932)\end{array}$ \\
\hline Spread(t-1) & $\begin{array}{c}-0.005^{\text {**** }} \\
(-3.353)\end{array}$ & $\begin{array}{c}0.000 \\
(0.130)\end{array}$ & $\begin{array}{c}0.000 \\
(0.441)\end{array}$ & $\begin{array}{l}0.005^{\text {**** }} \\
(4.290)\end{array}$ \\
\hline Ha: Soy Bea & Soy Meal & $\mathrm{W}=217.07^{* * *}$ & & \\
\hline Ha: Soy Me & Soy Bean & $\mathrm{W}=50.68^{* * * *}$ & & \\
\hline Ha: Soy Bea & Soy Oil & $\mathrm{W}=18.05^{* * * *}$ & & \\
\hline Ha: Soy Oil & oy Bean & $\mathrm{W}=61.86^{* * * *}$ & & \\
\hline $\mathrm{Q}(24)$ & 11.15 & 18.10 & 12.75 & 1.95 \\
\hline AIC & & -5.37 & & -5.28 \\
\hline Log Likelihs & & 20134.72 & & 19818.53 \\
\hline
\end{tabular}


The major market for soy meal, which usually accounts for around sixty percent of the combined soy meal and soy oil value, is the mixed-feed industry. Roughly eighty percent of soy meal production is for domestic consumption. On the other hand, soy oil is the major vegetable oil produced in the U.S. and roughly ninety percent of the production is consumed domestically. Given that soy meal is a relatively more important commodity in international markets, it may reflect international price movements and enjoy more liquidity than the soy oil contracts. Export value as well as market liquidity may explain some of the differences in two contract prices.

Table 4 reports results from the joint estimation of equations (1)-(5). For the sake of brevity, we only present the results from the variance and covariance equations. It should be noted, however, that the nonlinear estimations of mean equations (1) and (2) continued to support the evidence of bi -directional causality between the two futures returns, and the evidence that the soybean contract bears the burden of convergence in one case and not in the case of soy oil.

Table 4: Bivariate GARCH Model With Volatility Spillovers

\begin{tabular}{|c|c|c|c|c|}
\hline Variance Equation & SB & SM & SB & SO \\
\hline \multirow[t]{2}{*}{ Intercept } & $0.021^{* * * *}$ & $0.040^{* * *}$ & $0.020^{* * *}$ & $0.025^{* * *}$ \\
\hline & $(13.54)$ & $(18.13)$ & $(14.97)$ & $(13.64)$ \\
\hline \multirow[t]{2}{*}{ Lagged Conditional Variance } & $0.905^{* * * *}$ & $0.887^{* * *}$ & $0.919^{* * *}$ & $0.942^{* * *}$ \\
\hline & $(287.64)$ & $(251.63)$ & $(91.00)$ & $(546.92)$ \\
\hline \multirow[t]{2}{*}{ Lagged Own Shocks } & $0.068^{* * * *}$ & $0.073^{* * * *}$ & $0.076^{* * *}$ & $0.045^{* * * *}$ \\
\hline & $(22.19)$ & $(26.47)$ & (19.29) & $(25.46)$ \\
\hline \multirow[t]{2}{*}{ Intermarket Lagged Shock } & $0.0009^{* * * *}$ & $-0.0009^{* * *}$ & $0.021^{* * * *}$ & $0.039^{* * *}$ \\
\hline & $(3.21)$ & $(4.13)$ & $(4.19)$ & $(9.58)$ \\
\hline Ho: intermarket lagged shocks are equal & $\chi^{2}(1)=36.07$ & $\chi^{2}(1)=17.96^{* * *}$ & & \\
\hline
\end{tabular}

Conditional Covariance Equation

\begin{tabular}{|c|c|c|c|c|}
\hline Intercept & $\begin{array}{c}0.014^{* * *} \\
(10.03)\end{array}$ & & $\begin{array}{c}0.008^{* * *} \\
(8.10)\end{array}$ & \\
\hline Lagged Conditional Covariance & $0.907^{* * * *}$ & & $0.942^{* * *}$ & \\
\hline & $(333.38)$ & & $(1443.89)$ & \\
\hline Product of Lagged Residuals & $0.082^{* * *}$ & & $0.052^{* * *}$ & \\
\hline & $(28.42)$ & & $(23.51)$ & \\
\hline$\overline{\mathrm{Q}(8)}$ & 4.69 & 10.53 & 12.53 & 4.40 \\
\hline $\mathrm{Q}(24)$ & 22.52 & 21.99 & 19.55 & 10.03 \\
\hline Sign Bias t-Statistic & $1.80^{*}$ & $-2.31^{* *}$ & -0.59 & -0.84 \\
\hline System Log Likelihood & -7971.41 & & -6115.76 & \\
\hline
\end{tabular}

The coefficients for the lagged variances in the variance equations suggest considerable volatility persistence for both contracts. This may be indicating the effects of price limits on the futures prices of the Crush constituents. There is a strong evidence of bilateral volatility spillover between soybean and its two products. The coefficients on the intermarket lagged shocks are significant at the one percent level in soybean, soy meal and soy oil equations. According to Ross (1989), such evidence would be consistent with information arriving simultaneously in soybean, soy meal and soil oil markets. There is evidence of persistence in the covariance of the pairs of returns as indicated by the coefficients on $\sigma_{\mathrm{SB}, \mathrm{SMt}-1}$ and $\sigma_{\mathrm{SB}, \mathrm{SOt}-1}$. Finally, the diagnostics support the specification of the model. The $\mathrm{Q}(24)$ statistics for auto- 
correlation in the standardized residuals are insignificant at the one percent level and the sign bias statistic suggest that the standardized residuals are independent and identically distributed in two out of four cases. (see Engle and $\mathrm{Ng}$ (1993)).

We also consider the impact of the spread on the variability of its constituents. Given that the price behaviors associated with a contracting spread may be quite different from those associated with an expanding spread, we allow for an asymmetric relationship between the contract variance and changes in the spread. Equations (3), (4) and (5) are estimated with lagged changes in the spread as follows

$$
\begin{aligned}
& \sigma_{S B, t}=\alpha_{0}+\alpha_{1} \sigma_{S B, t-1}+\alpha_{2} \varepsilon_{S B, t-1}^{2}+\alpha_{3} \cdot \eta^{+}{ }_{t} \cdot Z_{t-1}+\alpha_{4} \eta^{-} \cdot Z_{t-1}+u_{S B, t} \\
& \sigma_{S M, t}=\beta_{0}+\beta_{1} \sigma_{S M, t-1}+\beta_{2} \varepsilon_{S M, t-1}^{2}+\beta_{3} \cdot \eta^{+}{ }_{t} \cdot Z_{t-1}+\beta_{4} \eta^{-} \cdot Z_{t-1} u_{S M, t} \\
& \sigma_{S B, S M, t}=\pi_{0}+\pi_{1} \sigma_{S B, S M, t-1}+\pi_{2} \varepsilon_{S B, t-1} \varepsilon_{S M, t-1}+\pi_{3} \eta^{+}{ }_{t} \cdot Z_{t-1}+\pi_{4} \eta_{t}^{-} \cdot Z_{t-1}+u_{S B, S M, t}
\end{aligned}
$$

where $\mathrm{z}_{\mathrm{t}}$ is the change in the spread at $\mathrm{t}\left(\mathrm{z}_{\mathrm{t}}=\Delta\left(\operatorname{lnSB}_{\mathrm{t}}-\operatorname{lnSM}_{\mathrm{t}}\right)\right), \eta^{+}$is a dummy that takes on the value of 1 if $\mathrm{z}_{\mathrm{t}}$ is positive and $\eta^{-}=\left(\eta^{+}-1\right)$. Larger $\alpha_{3}$ and $\beta_{3}$ coefficients (relative to $\alpha_{4}$ and $\beta_{4}$, respectively) will be consistent with the notion that positive movements in spreads are associated with relatively greater volatility in the constituents. Similarly, a larger $\pi_{3}$ coefficient compared to $\pi_{4}$ will suggest greater covariance (co-movement in volatility) when the spread is rising.

Table 5 reports the results for the joint solution of (1), (2), and (6), (7) and (8). The mean equations (not presented) continue to support the earlier evidence of a bi-directional causal relationship between the two return series pairs, and the convergence burden of the three contracts. The lagged variance coefficients in the top panel of the table continue to be significant. Note that the coefficient for volatility persistence in both equations stay the same as before or increase as compared with Table $4 .{ }^{4}$ This evidence is consistent with the notion that increases in the spread prolong the soy meal and soy oil price-adjustment process.

It is well known that volatility in commodity prices is persistent. For instance, in the absence of winter freeze in Florida, orange juice futures prices continue to drop. Thus futures prices tend to react to both good and bad news in the market with consistency. Statistically, this phenomenon is shown by positive autocorrelation in returns. Furthermore, all known financial and commodity markets exhibit volatility clustering: days of high variability follow days of high variability; days of relative tranquility are also clustered. Volatility clustering may be caused by information clustering or trader.

The coefficients on the negative changes in spreads (i.e., $\eta^{-} \cdot \mathrm{z}_{\mathrm{t}-1}$ ) are positive and roughly equal (based on $\chi^{2}$ statistics) to the coefficients on the positive changes in spreads in the variance equations. This evidence suggests that the prices are generally equally volatile when the spread is expanding or contracting, and that the narrowing of the spread leads to relatively closer co-movements in the underlying contracts. However, the evidence suggests that large changes in the spread (whether negative or positive) are followed by heightened covariance of the two sets of contracts. Our tests also indicate that while positive spreads results in asymmetric volatility in soybeans and soy meal contracts, that is no the case in the soy oil markets. Furthermore, negative spreads in both bilateral models contribute equally to market volatility as shown by insignificant $\chi^{2}$ statistics.

An intriguing aspect of the results presented so far is that even while we find evidence of bi-directional causality between the two pairs of contracts, there is also strong evidence that soybean bears the burden of convergence at least in one of the cases. However, in the case of soy oil, for which the market is more liquid than soy meal, neither soybeans nor soy oil contracts bear the burden of convergence. For example, the price spread in any period is expected to widen once

\footnotetext{
${ }^{4}$ Unfortunately, testing the significance of the changes in the coefficients across the models is not feasible. However, note that the lagged variance coefficient is about the same size of that in the model without the spread variable.
} 
two contract prices diverge. This is evidenced by the positive and significant coefficient of $\lambda_{\text {so }}$ in the soy oil VAR equation. These findings may be indicating some liquidity differences for the three contracts.

One of the bases for interpreting the relative price adjustments has thus far been volatility spillover. Specifically, the premise has been that increased volatility in data is symptomatic of information processing. However, while pronounced volatility could be due to the amount of information reaching the market, persistence in volatility may also be a reflection of the time it takes market participants to fully process the information (Diebold and Nerlove (1989)). The significance of volatility persistence in both Tables 4 and 5 may indicate that the Crush futures markets participants are relatively slow in processing the new information.

Table 5: Bivariate GARCH Model With Spreads

\begin{tabular}{|c|c|c|c|c|}
\hline Variance Equation & SB & SM & SB & SO \\
\hline \multirow[t]{2}{*}{ Intercept } & $0.019^{* * *}$ & $0.028^{* * *}$ & $0.056^{* * *}$ & $0.094^{* * *}$ \\
\hline & $(5.64)$ & $(7.50)$ & $(5.06)$ & $(14.97)$ \\
\hline \multirow[t]{2}{*}{ Lagged Conditional Variance } & $0.902^{* * * *}$ & $0.897^{* * *}$ & $0.905^{* * *}$ & $0.926^{* * * *}$ \\
\hline & $(200.33)$ & $(235.25)$ & $(213.13)$ & $(276.01)$ \\
\hline \multirow[t]{2}{*}{ Lagged Own Shock } & $0.091^{* * *}$ & $0.087^{* * *}$ & $0.088^{* * *}$ & $0.063^{* * *}$ \\
\hline & $(18.60)$ & $(20.90)$ & (19.64) & $(21.68)$ \\
\hline \multirow[t]{2}{*}{ 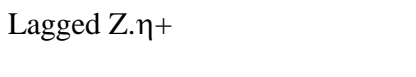 } & 0.008 & $0.116^{* * *}$ & $0.047^{* * *}$ & $0.083^{* * *}$ \\
\hline & $(0.56)$ & $(6.84)$ & $(2.76)$ & $(3.03)$ \\
\hline \multirow[t]{2}{*}{ Lagged Z.ク- } & 0.055 & $0.162^{* * *}$ & $0.042^{* * *}$ & $0.071^{* * *}$ \\
\hline & $(1.56)$ & $(3.17)$ & $(3.53)$ & $(3.57)$ \\
\hline Ho: Z. $\eta+=Z . \eta-$ & $\chi^{2}(1)=2.83^{*}$ & $\chi^{2}(1)=1.28$ & $\chi^{2}(1)=0.68$ & $\chi^{2}(1)=1.84$ \\
\hline 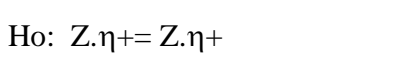 & $\chi^{2}(1)=19.40^{* * *}$ & & $\chi^{2}(1)=1.11$ & \\
\hline 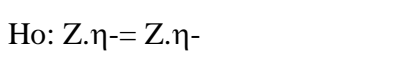 & $\chi^{2}(1)=2.30$ & & $\chi^{2}(1)=1.40$ & \\
\hline \multicolumn{5}{|l|}{ Conditional Covariance Equation } \\
\hline \multirow[t]{2}{*}{ Intercept } & $0.012^{* * * *}$ & & & $0.018^{* * * *}$ \\
\hline & $(11.95)$ & & & $(14.13)$ \\
\hline \multirow[t]{2}{*}{ Lagged Conditional Covariance } & $0.806^{* * *}$ & & & $0.737^{* * * *}$ \\
\hline & $(223.33)$ & & & $(78.04)$ \\
\hline \multirow[t]{2}{*}{ Product of Lagged Residuals } & $0.091^{* * *}$ & & & $0.081^{* * * *}$ \\
\hline & $(23.52)$ & & & $(22.99)$ \\
\hline \multirow[t]{2}{*}{ 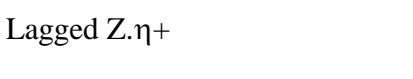 } & $0.717^{* * * *}$ & & & $0.673^{* * * *}$ \\
\hline & (12.89) & & & $(4.49)$ \\
\hline \multirow[t]{2}{*}{ 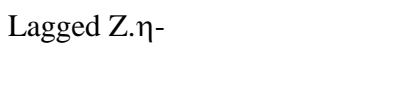 } & $0.991^{* * * *}$ & & & $0.921^{* *}$ \\
\hline & $(2.97)$ & & & $(2.13)$ \\
\hline 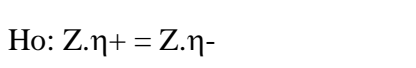 & $\chi^{2}(1)=0.23$ & & & $\chi^{2}(1)=18.45$ \\
\hline $\mathrm{Q}(24)$ & 26.16 & 26.29 & 27.22 & 21.24 \\
\hline Sign Bias t-Statistic & 1.23 & -1.65 & 1.49 & -0.61 \\
\hline System Log Likelihood & -12298.62 & & & -60780.44 \\
\hline
\end{tabular}

Notes: Returns and conditional variance equations are estimated in a system assuming variance correlations are constant. The sign bias test shows whether positive and negative innovations affect future volatility differently from the model prediction (see Engle and $\mathrm{Ng}(1993))$. ***, and **, represent significance at 1 , and 5 percent levels, respectively. 


\section{SUMMARY AND CONCLUSIONS}

We investigate the price discovery process between soybean futures and the Crush constituents, soy meal and soy oil, in the U.S. The pricing relationship between these commodities may have implications for trading strategies, imply market inefficiencies, or address the derived demand theory. Furthermore, we may find evidence regarding market microstructure theories, which maintain that the price information disseminates from more liquid markets.

In the U.S. soybean, soy meal, and soy oil futures contracts are traded on the Chicago Board of Trade. Price fluctuations in these products affect consumers and livestock feed producers, among others. Thus, price volatility of soybean Crush constituents has significant income effect beyond the market for soybeans and its Crush products.

Our test results suggest a strong bi-directional causality in futures prices. We also find that the soybean contract bears the burden of convergence between soybean and soy meal prices. However, the same is not true in reference to soy oil prices. Thus, soy meal contracts may be more liquidity than soybeans and soy oil. The statistical findings show evidence of considerable volatility persistence for all contracts. Also, there is strong evidence of volatility spillover among these markets. Thus, price information maybe reaching the three markets simultaneously. There may be several explanations for this price behavior. One is that soy bean and its derivatives are international commodities affected by world macroeconomic conditions. It may be argued that traders in the U.S. futures markets for soybeans and the Crush constituents are price takers. This would explain the lack of clear evidence of price leader ship in any of the Crush constituents' market. Another possibility is that liquidity differences among the markets for soybeans, soy meal, and soy oil maybe negligible. Furthermore, we do not find unequivocal statistical evidence in support for the derived demand theory.

While the pronounced volatility could be due to the amount of information reaching the market, persistence in volatility may also be a reflection of the time it takes market participants to fully process the information. The evidence of volatility persistence in this study is consistent with those of other commodities and financial instruments.

\section{REFERENCES}

1. Baillie, R. T. and T. Bollerslev, 1990, A Multivariate Generalized ARCH Approach to Modeling Risk Premia in Forward Foreign Exchange Rate Market, Journal of International Money and Finance, 9, 309-324.

2. Bollerslev, T., 1986, Generalized Autoregressive Conditional Heteroskedasticity, Journal of Econometrics, 31, 307-327.

3. Blume, L., D. Easley, and M. O'Hara, 1994, Market Statistics and Technical Analysis: The Role of Volume, Journal of Finance, 49, 153-181.

4. Chan, K., K. C. Chan, and G. A. Karolyi, 1991, Intraday Volatility in the Stock Index and Stock Index Futures Markets, Review of Financial Studies, 4, 657-684.

5. Chatrath, A. and F. Song, 1998, Information and the Volatility in futures and Spot Markets: The Case of the Japanese Yen, Journal of Futures Markets, 18, 201-224.

6. Conrad, J. and G. Kaul, 1991, Asymmetric Predictability of Conditional Variance, Review of Financial Studies, 4, 597-622.

7. Conrad, J., A. Hameed, and C. Niden, 1994, Volume and Autocovariances in Short-Horizon Individual Security Returns, Journal of Finance, 49, 1305-1329.

8. Dickey, David A. and W. A. Fuller, 1979, Distribution of the Estimators for Autoregressive Time Series With a Unit Root, Journal of American statistical Association, 74, 427-31.

9. Diebold, F. X. and M. Nerlove, 1989, The Dynamics of Exchange Rate Volatility: A Multivariate Latent Factor ARCH Model, Journal of Applied Econometrics, 4, 1-21.

10. Diebold, F. X., J. Gardeazabal, and K. Yilmaz, 1994, On Cointegration and Exchange Rate Dynamics, Journal of Finance, 49, 727-735.

11. Engle, R. F., 1982, Autoregressive Conditional Heteroskedasticity and Estimates of the Variance of U.K. Inflation, Econometrica, 50, 987-1008. 
12. and V. K. Ng, 1993, Measuring and Testing the Impact of News on Volatility, Journal of Finance, 48, 1749-1778.

13. _ V. K. Ng, and M. Rothschild, 1990, Asset Pricing with a Factor ARCH Co-variance Structure: Empirical Estimates or Treasury Bills, Journal of Econometrics, 45, 213-238.

14. _ D. M. Lilien, and R. P. Robins, 1987, Estimating Time Varying Risk Premia in the Term Structure: The ARCH-M Model, 55, 391-407.

15. Garbade, K. D. and W. L. Silber, 1979, Dominant and Satellite Markets: A Study of Dually-Traded Securities, Review of Economics and Statistics, 61, 455-460.

16. Hamao, Y., R. W. Masulis, and V. Ng, 1990, Correlations in Price Changes and Volatility Across International Stock Markets, Review of Financial Studies, 3, 281-308.

17. Harris, F. H., T. H. McInish, G. L. Shoesmith, and R. A. Wood, 1995, Cointegration, Error Correction, and Price Discovery on Informationally Linked Security Markets, Journal of Financial and Quantitative Analysis, 30, 56379.

18. Hasbrouck, J., 1995, One Security, Many Markets: Determining the Contribution to Price Discovery, Journal of Finance, 50, 1175-1199.

19. Hsieh, D. A., 1989, Testing for Nonlinear Dependence in Exchange Rate Changes, Journal of Business, 62, 339368 .

20. Johansen, S. and K. Juselius, 1990, Maximum Likelihood Estimation and Inference on Cointegration - with Applications to the Demand for Money, Oxford Bulletin of Economics and Statistics, 52, 169-210.

21. Karolyi, G. A. and R. M. Stulz, 1996, Why Do Markets Move Together? An Investigation of US-Japan Stock Return Comovements, Journal of Finance, 51, 951-986.

22. Kim, O. and R. E. Verrecchia, 1991, Market Reactions to Anticipated Announcements, Journal of Financial Economics 30, 273-310.

23. Kyle, A. S., 1985, Continuous Auctions and Insider Trading, Econometrica 53, 1315-1336.

24. Phillips, P. C. B. and P. Perron, 1986, Testing for Unit Roots in Time Series Regression, Discussion Paper, New Haven, Conn.:Yale University, Cowles Foundation.

25. Roell, A., 1992, Comparing the Performance of Stock Exchange Trading Systems, in The Internationalization of Capital Markets and the Regulatory Response, J. Fingleton and D.Schoenmaker, eds., Graham and Trotman, London.

26. Ross, S., 1989, Information and Volatility: The No-Arbitrage Approach to Timing and Resolution of Irrelevancy, Journal of Finance, 44, 1-17.

27. Shiller, R., 1979, The Volatility of Long-Term Interest Rates and Expectations Models of Term Structure, Journal of Political Economy, 87, 1190-1219.

28. Singleton, K. J., 1980, Expectations Models of the Term Structure and Implied Variance Bounds, Journal of Political Economy, 88, 1159-1176.

29. Verrecchia, R. E., 1981, On the Relationship Between Volume Reaction and Consensus of Investors: Implications for Interpreting Tests of Information Content, Journal of Accounting Research 19, 271-283.

30. Weiss, A., 1984, ARMA Models with ARCH Errors, Journal of Time Series Analysis, 5, 129-143. 